\title{
Physical Activity and Obesity in Children 11 and 14 Years Old in Tirana
}

ISSN: 2577-1914

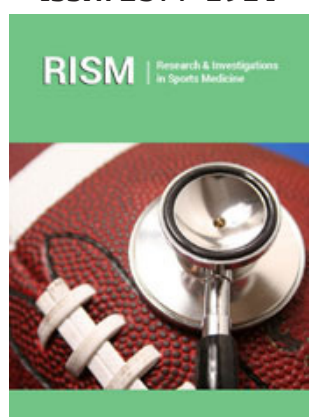

*Corresponding author: QeleshiAnesti, Sports University of Tirana, Albania

Submission: 海July 10, 2020

Published: :

Volume 7 - Issue 1

How to cite this article: Qeleshi Anesti. Physical Activity and Obesity in Children 11 and 14 Years Old in Tirana. Res Inves Sports Med, 7(1): RISM.000653. 2020. DOI: $10.31031 /$ RISM.2020.07.000653

Copyright@ Qeleshi Anesti, This article is distributed under the terms of the Creative Commons Attribution 4.0 International License, which permits unrestricted use and redistribution provided that the original author and source are credited.

\section{Qeleshi Anesti*}

Sports University of Tirana, Albania

\section{Abstract}

Working with children requires a special approach due to the widedifferences that are seen within and between diverse gender and age groups.We hypo these that we had a possibility to get information on the relationship between obesity, physicalactivity, and inactivity in children 11 and 14-years.We expect that boys will be more active than girls.We expect that children from local area are leaner than central area.

Subjects and methods: Cross section survey of 306 boys and 313 girls,(11 and 14 years old)-randomly selected in 6 different schools in Tirana placed in the center and local area on overweight and obesity phenomena

Conclusion: The data of this study show a non-significant situation or problem of overweight and obesity in children, both in center and local area. A contrary what believed, there is an underweight problem in girls11 years from local area

\section{Introduction}

Physical activity has a range of benefits during childhood including healthy growth and Development, assistance in maintenance of energy balance, and improvements in psychological and social interaction (Department of Health, 2004). Participation in physical activity during childhood may also have an indirect effect on risk-factors for cardiovascular disease, by helping children to prevent excess weight gain or helping overweight children to lose weight (Department of Health, 2004). There is a close relationship between physical activity, physical fitness, and health in adults $[1,2]$ and since it is generally accepted that the onset of many chronic diseases occurs in early childhood [3], children and youth are considered important target groups for preventive intervention. Intervention generally should begin at an early age for two reasons:

1. To ensure normal growth and development [4].

2. Due to evidence indicating those children's lifestyle habits and risk factors tend to persist into adult life [5-7].

This second reason relates especially to variables like overweight, high blood pressure, physical inactivity, unfavorable lipid profile, and inadequate cardiorespiratory fitness. Although chronic diseases are infrequent in youth, risk factors are present and track from childhood to adult life $[8,9]$. Specific criteria to define risk are more difficult to establish in children and adolescents than in adults.

\section{Purpose of this study}

To objectively measure the level of physical activity in a representative population of Children and youth in Tirana from six different school that represent different areas of the city. To study the actual situation of obesity and giving the modest prevention ideas. To study the obesity and level of physical activity in 11-and 14-year-old children, differencing both in age and gender. To give a clear and critical panorama to the problem of obesity among children and the differences from center and local area. To underline the role of PA in reducing obesity problems and other diseases. To make sensible the academic opinion about these topics.

\section{Subjects and methods}

Cross section survey of 306 boys and 313 girls 11 and 14 years old, randomly selected in 6 different schools in Tirana placed in the center and local area on overweight and obesity. 800 
questionnaires. assessment for both sexes (selected from PEACH questionnaires from European Youth Heart Study). Objective measurement of height, weight and waist circumference were obtained. We expect that children from local area are leaner and more active than central area. Because of the difference in the socioeconomic status, and peer/ family support, will be a difference in BMI, waist circumference and physical activity between children from the center to the local area.

\section{The Current Epidemic of Obesity and Inactivity}

\section{Obesity}

The World Health Organization has now tentatively recommended the use of BMI - for age as indicator of overweight or obesity [10]. Although BMI may not be a very precise indicator of fatness for an individual many studies support the use of BMI as an indicator of fatness for a larger population $[11,12]$.

\section{Inactivity lifestyle}

The minimum exercise prescription necessary to improve $\mathrm{VO}_{2}$ $\max (20$ to 30 minutes of endurance exercise performed three times per week at 50-70 \%of $\mathrm{VO}_{2}$ max) may eventually improve cardiorespiratory fitness over several weeks [13].

\section{Nutrition and Basal Metabolic Rate}

The food choices of their children. This factor probably has some reality. An early study measuring RMR and energy intake in 3-4 years -old children found that children with at least one obese parent consumed less energy, bur also expended less energy, especially in physical activity, than those with no obese parents [14]. Studies have shown some clear genetic bases for obesity. For example, identical twins brought up separately, in different environments with different adult models, have shown a remarkable tendency toward similar fatness or thinness [15]. Other studies have shown that rapid maturation is associated with greater obesity in adulthood [1].

\section{Results (Figures 1-3)}

Now we will be focus on PEACH questionnaires from European Youth Heart Study.

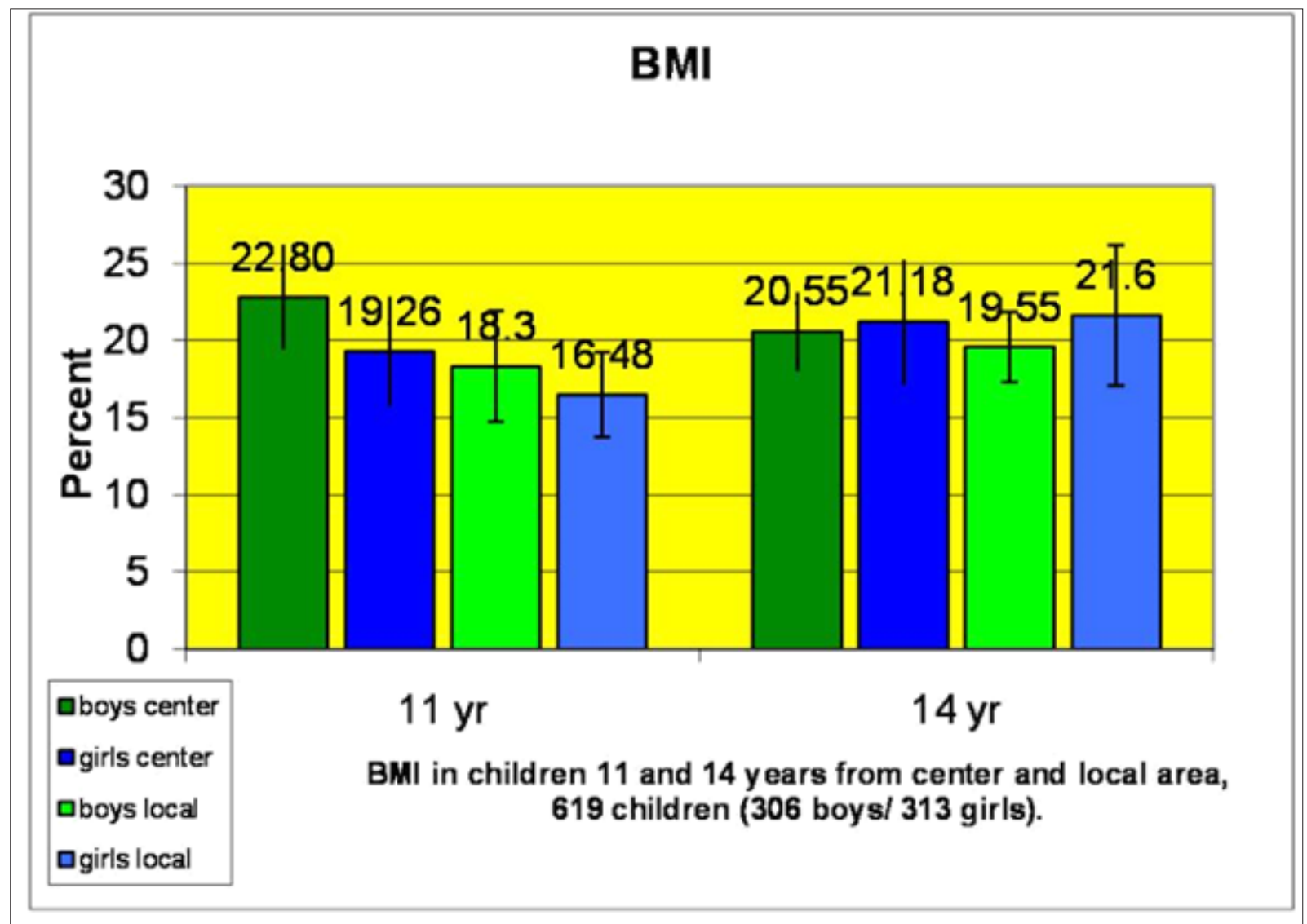

Figure 1: BMI in children 11 years old that live in local area have a lower value compared with those who live in center area. In the meantime, girls compared with boys have an average BMI 16.48. Boys 11 years, that live in center have a significant value (22.80) compared with other even with 14 years. Girls 11 years old, from local area, have a BMI under 17(16.48), Children 11 years old have a different spectrum of BMI compared to children 14 years. Boys 14 years have approximately the same value in local and center area. 


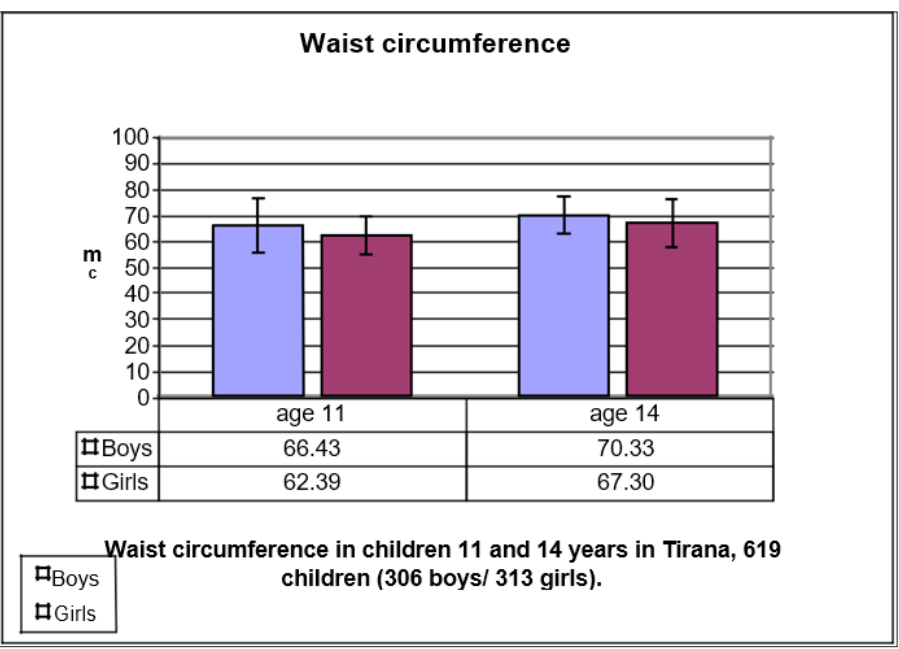

Figure 2: Girls 11 years old have lower value compared with other age and sex. Boys 14 years old have a higher value than the other, $70.33 \mathrm{~cm}$.

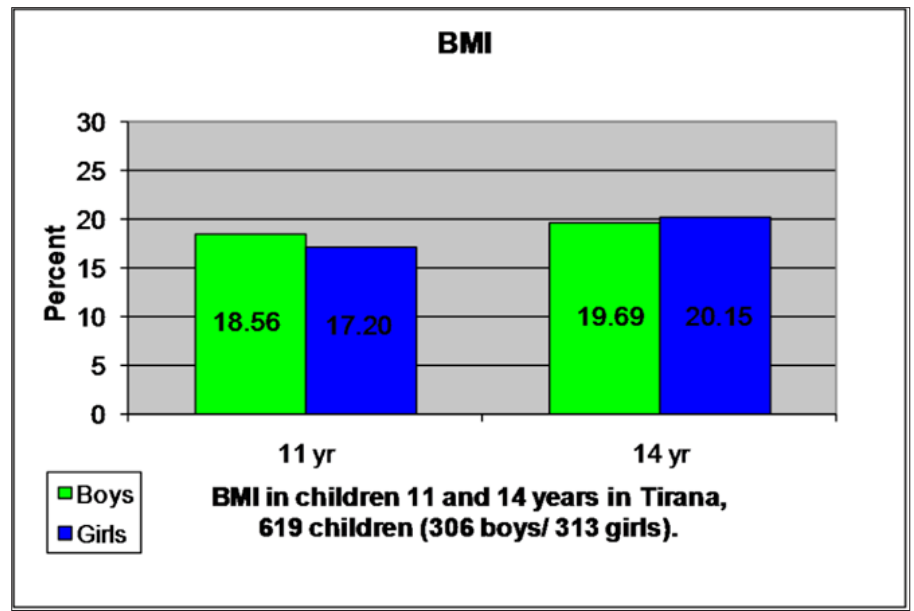

Figure 3: BMI in boys 11 years is 18.56 , little bit higher than girls, but in 14years old they are approximately the same. BMI in boys and girls 14 years old have approximately the same value $(19.69,20.15)$.

Physical activity questionnaires (Figures 4 \& 5)

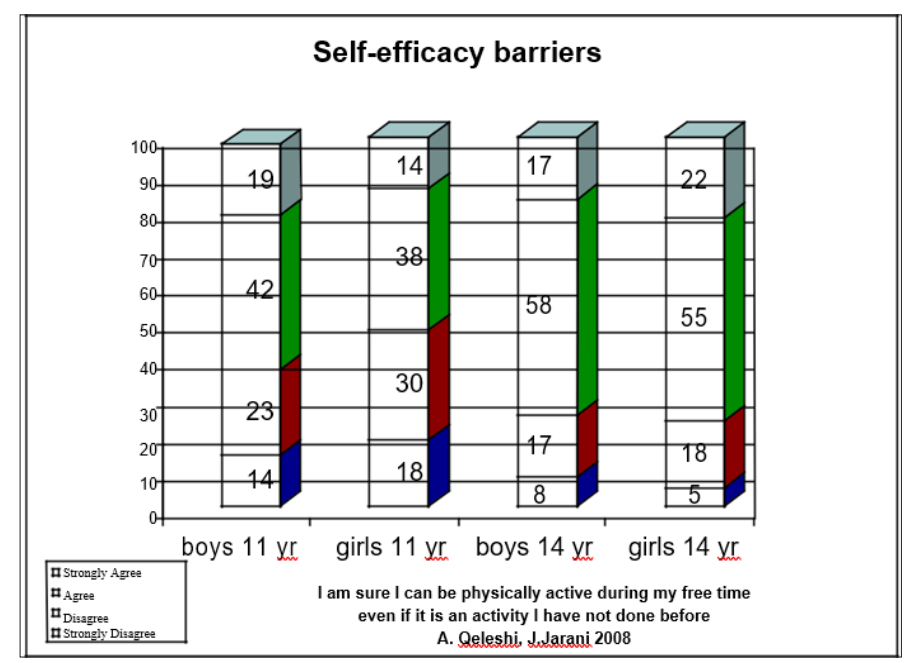

Figure 4: The most of boys and girls 11 years old agree (52\% \& 58\%) and strongly agree (19\% \& $12 \%)$. Boys and girls 14 years old agree $(60 \%)$ and strongly agree $(24 \% \& 15 \%)$. 


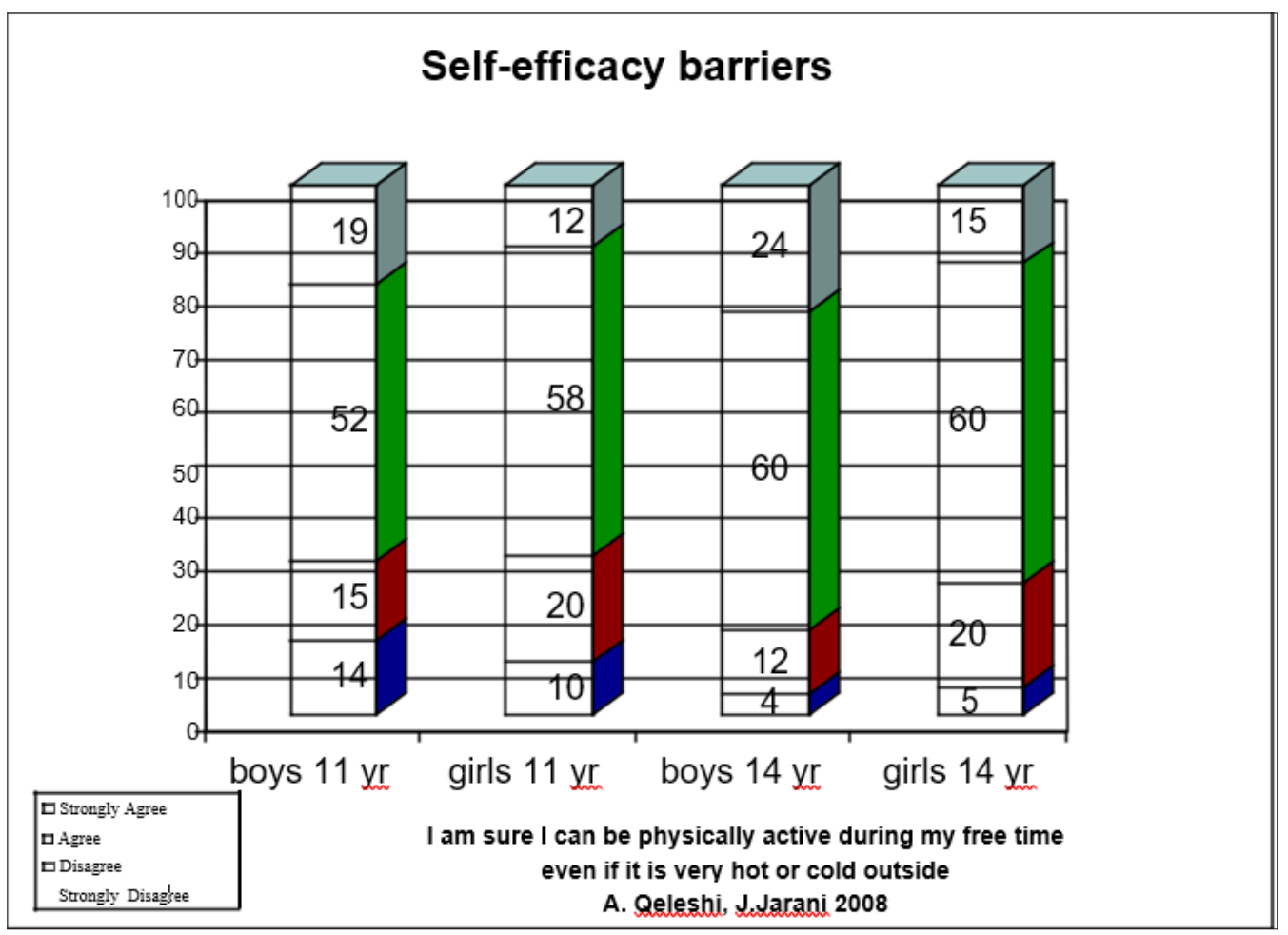

Figure 5: Children 14 years old agree (58\% boys and 55\% girls) and strongly agree (17\% \& 22) \& Children 11 years old, that agree (42\% \& 38\%) and strongly agree (19\% \& 14\%).

The question - How often do you good friend encourage you to exercise or play sport? (Figure 6)

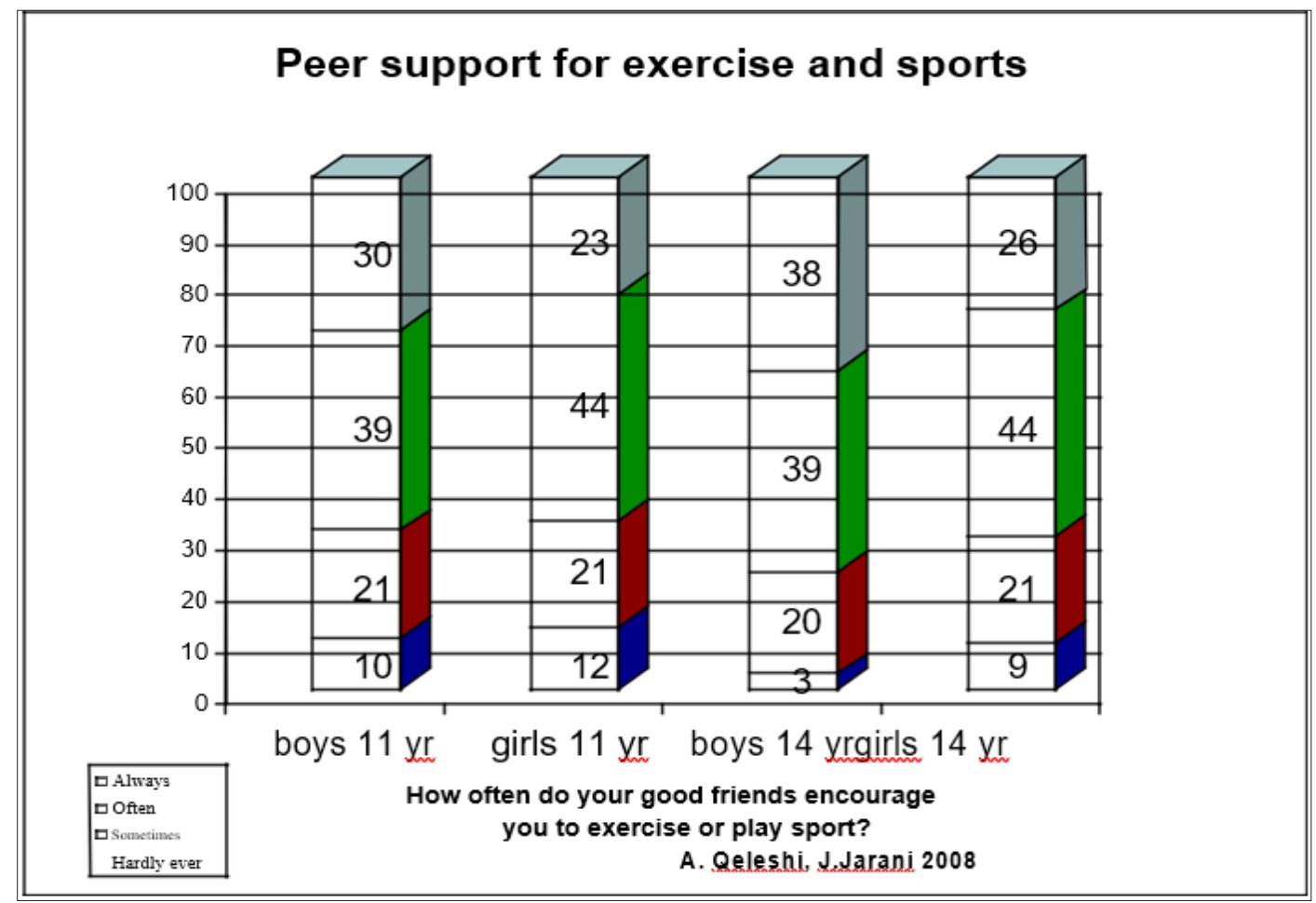

Figure 6: For 11 years old agree (39\% \& 44) and strongly agree (30\% \& 23\%), For 14 years old agree $(39 \%$ \& 44\%) and strongly agree (38\% \& 26). 
The question - How often do you good friends exercise or play with you? (Figure 7)

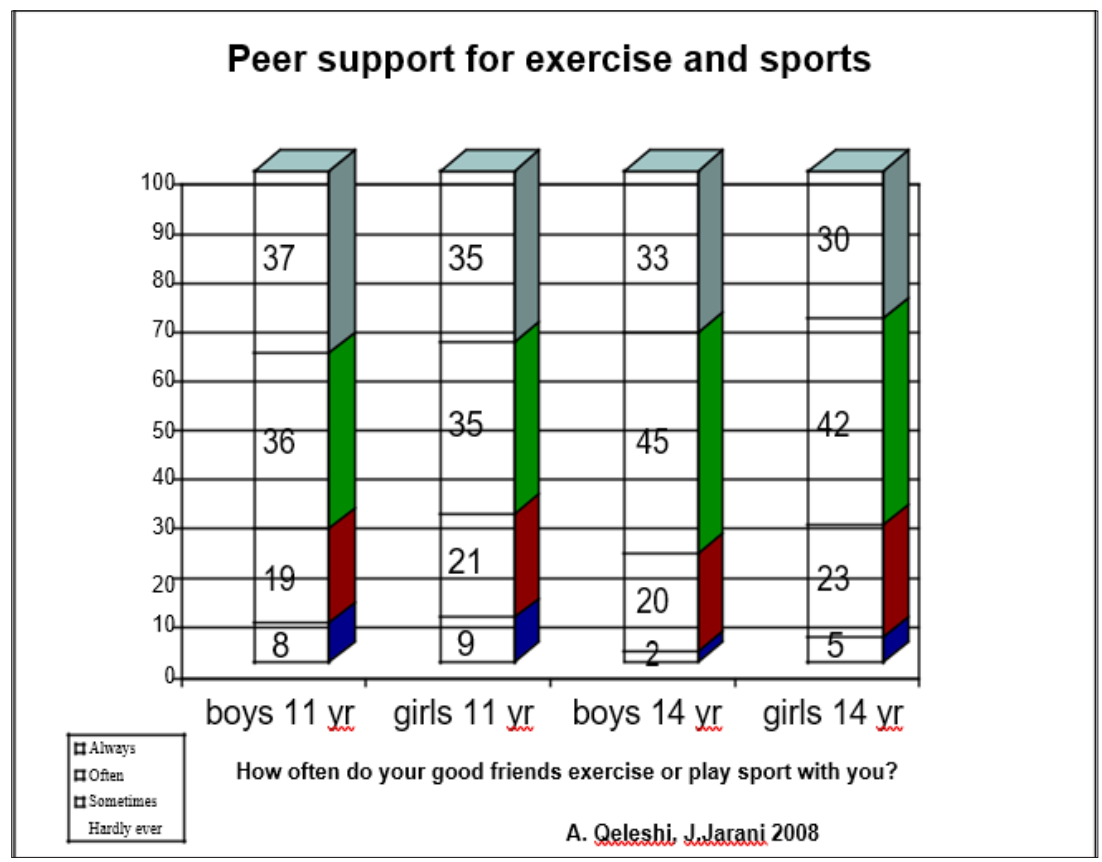

Figure 7: For 11 years old agree (36\% \& 35) and strongly agree (37\% \& 35\%), For 14 years old agree (45\% \& 42\%) and strongly agree $(38 \% \& 30)$.

\section{Discussion}

I want to open my discussion with a good paragraph. Of course, not all scientific research is equally necessary for participation in sports and moreover not all are equally valid. Some researches worth more while some of them are treated more carefully to allow you to willingly study their research, but it is worth noting that science is not a final answer but an ongoing process - (Gill L. Dianne. Psychological Dynamics of Sport. USA 1986). In science there is a postulate that the data science should be honest, simple and true. The data in this article are like that.

The study is shown in the following figures: BMI in children 11 years old that live in local area have a lower value compared with those who live in center area. In the mean time girls compared with boys have an average BMI 16.48. Boys 11 years, that live in center have a significant value (22.80) compared with other even with 14 years. Girls 11 years old ,from local area, have a BMI under $17(16.48)$,that mean we have here underweight problem. Children 11 years old have a different spectrum of BMI compared to children 14 years old that do not have many differences between them. Boys 14 years have approximately the same value in local and center area. Girls 11 years old have lower value compared with other age and sex and in the mean time the figure shows non-significant differences between two sex, a contrary what believed girls have lower value for both ages. Boys 14 years old have a higher value than the other, $70.33 \mathrm{~cm}$ and this is understanding because of their chronological age (hormonal changes).

BMI in boys 11 years is 18.56 , little bit higher than girls, but in 14 years old they are approximately the same. For both ages, seems that do not have problem with overweight and obesity a contrary for girls 11years old we are near underweight problem. BMI in boys and girls 14 years old have approximately the same value (19.69, 20.15), but not significant for our topic. It is a considerable percent of both sex and ages that doing, in their free time physical activity even it is very hot or cold outside. The most of boys and girls 11 years old agree (52\% \& 58\%) and strongly agree (19\% \& 12\%). Boys and girls 14 years old agree (60\%) and strongly agree $(24 \%$ \& $15 \%)$.

Boys in both ages seems to have more predisposition to be active even if cold or hot outside. Most impressive are children 14 years old agree (58\% boys and 55\% girls) and strongly agree $(17 \%$ \& 22), \& that shows a significant "love" for physical activity during free time even if it is an activity never done before. Little bit lower is with children 11 years old, that agree ( $42 \%$ \& $38 \%$ ) and strongly agree $(19 \% \& 14 \%)$. Perhaps these data depending for their ages and their attitude toward new games, but at least it not bad. As we see the social support, or peer support is in high level. For 11 years old agree (39\% \& 44) and strongly agree (30\% \& 23\%), where in total boys are better than girls. For 14 years old agree (39\% \& 44\%) and strongly agree $(38 \% \& 26)$ where still in total boys are better than girls

The figure speaks itself about encourage, peer support, and motivation. The situation it not bad, especially for the girls 11 years old. The data from figure 7 shows an optimism spirit and between children and a desire for playing and exercise together. For 11 years old agree (36\% \& 35$)$ and strongly agree (37\% \& 35\%), where in total boys are better than girls. For 14 years old agree ( $45 \%$ \& $42 \%$ ) 
and strongly agree $(38 \%$ \& 30$)$ where still in total boys are better than girls. Data show that boys have little bit higher value compared with girls. A pilot project will be very positive for facilities in using of Summer Schools and creating of Boy Scout Centers in our region in function of better and happy life. We need a wide range of research that will include more schools in Tirana and it will be very useful for our purpose and ideas for creating a map project of obesity and overweight in our city, that actually does not exist and is not done before. We need further study in children from 11-14 years to see if the problem of obesity is near or not, as an enemy for our children, as a common enemy of our life.

\section{Conclusion}

The data of this study show a non-significant situation or problem of overweight and obesity in children. We found in children 11 and 14 years old the same physical active participation in boys and girls. Boys are more active than girls. In children 11 years we found the same BMI and waist circumference for both sexes, showing non-significant data for overweight and obesity. We have an underweight problem in girls11 years from local area. Physical active during my free time even it is very hot or cold outside. Boys in both ages seems to have more predisposition to be active even if cold or hot outside. Most impressive are children 14 years old agree (58\% boys and $55 \%$ girls) and strongly agree $(17 \%$ \& 22$) \&$ that shows a significant "love" for physical activity during free time. For 14 years old agree (39\% \& 44\%) and strongly agree (38 \% \& 26) where still in total boys are better than girls. The data shows an optimism spirit and between children and a desire for playing and exercise together.

\section{References}

1. Ness AR, Powles JW (1997) Fruit and vegetables, and cardiovascular disease: a review. Int J Epidemiol 26 (1): 1-13.

2. US Department of Health and Human Services (1996) Physical activity and health: A report of the surgeon general. U.S. Department of Health and Human Services, Centers for Disease Control and Prevention, National Center for Chronic Disease Prevention and Health Promotion, USA, pp. 1-277.
3. Berenson GS, Srinivasan SR, and Nicklas TA (1998) Atherosclerosis: a nutritional disease of childhood. Am J Cardiol 82(10B): 22T-9T.

4. Malina RM, Bouchard C (1991) Physical activity as a factor in growth, maturation, and performance. growth, maturation, and physical activity. ( $2^{\text {nd }}$ edn), Human Kinetics, Champaign, Illinois, USA, pp. 371-90.

5. Andersen LB, Haraldsdottir J (1993) Tracking of cardiovascular disease risk factors including maximal oxygen uptake and physical activity from late teenage to adulthood. An 8-year follow-up study. J Intern Med 234(3): 309-315.

6. Berenson GS, McMahan CA, Voors AW (1980) Cardiovascular risk factors in children: The Bogalusa heart study. Oxford University Press, Oxford, USA.

7. Kemper HC, Snel J, Verschuur R, Storm-van EL (1990) Tracking of health and risk indicators of cardiovascular diseases from teenager to adult: Amsterdam Growth and Health Study. Prev Med 19(6): 642-655.

8. Goran MI, Malina RM (1999) Fat distribution during childhood and adolescence: implications for later health outcomes. Am J Hum Biol 11(2): 187-188

9. Rolland-Cachera MF, Bellisle F, Deheeger M, Pequignot F, Sempe M (1990) Influence of body fat distribution during childhood on body fat distribution in adulthood: a two-decade follow-up study. Int J Obes Relat Metab Disord 14(6): 473-481.

10. WHO (1995) Physical status: the use and interpretation of anthropometry. WHO Technical report Series\# 854. WHO Geneva.

11. Deurenberg P, Westrate JA, Seidell JC (1991) Body mass index as a measure of body fatness: age - and sex - specific prediction formulas. British Journal of Nutrition 65(2): 105-114.

12. Pietrobelli A, Faith MS, Allison DB, Gallagher D, Ciumello G, et al. (1998) Body mass index as a measure of adiposity among children and adolescents: a validation study. Journal of Pediatrics 132(2): 204-210

13. Anonymous (1990) Position stand on "The recommended quality and quality of exercise for developing and maintaining cardiorespiratory and muscular fitness in healthy adults:" Medicine and Science in sport and Exercise 22: 265 -274.

14. Griffiths M, Payne PR (1976) Energy expenditure in small children of obese and non-obese parents. Nature 260(5553): 698-700.

15. Newman HH, Freeman FN, Karl J Holzinger (1937a) Twins: A study of heredity and Environment of Chicago Press, Chicago, USA. 